\title{
Optimal Outcome Factors In Maternity And Newborn Care For Inpatient (Hospital Maternity Ward-HMW) And Outpatient Deliveries (Outhospital Maternity Clinics -OMC)
}

\section{Azra Lukač ( $\square$ azra430@hotmail.com )}

Community Health Center, Rožaje

Nenad Šulović

Department of Gynecology and Obstetrics, Faculty of Medicine,University in Priština- Kosovska Mitrovica

Aleksandra llić Institute of Preventive Medicine, Faculty of Medicine, University in Priština- Kosovska Mitrovica Milica Mijović

Institute of Pathology, Faculty of Medicine, University in Priština- Kosovska Mitrovica

Dijana Tasić

Clinic of Gynecology and Obstetrics "Narodni Front", Belgrade

\section{Sonja Smiljić}

Institute of Physiology, Faculty of Medicine, University in Priština- Kosovska Mitrovica

\section{Research Article}

Keywords: Ol score, inpatient maternity ward, outpatient maternity clinic

Posted Date: June 2nd, 2021

DOI: https://doi.org/10.21203/rs.3.rs-529449/v1

License: (c) (i) This work is licensed under a Creative Commons Attribution 4.0 International License. Read Full License

Version of Record: A version of this preprint was published at BMC Pregnancy and Childbirth on December 1st, 2021. See the published version at https://doi.org/10.1186/s12884-021-04319-x. 


\section{Abstract}

Background and objectives: The aim of this study was to use the Optimality Index (OI-US) to initiate the possibility of developing an adequate national-level database for women with low- and medium-risk pregnancies but also to assess the feasibility and possible application in inpatient and outpatient delivery settings. Numerous worldwide associations support the option of women giving birth at maternity outpatient clinics or even at home. The assessments of requirements that need to be met and what could be characterized as the birth potential constitute the basis for making the right decision regarding childbirth.

Materials and Methods: The study is based on a prospective follow-up of pregnant women and new mothers (100 participants) who were monitored and gave birth at the hospital maternity ward (HMW) and pregnant women and new mothers (100 participants) who were monitored and gave birth at the outhospital maternity clinics (OMC). Selected patients were classified according to the criteria of low- and medium-risk and each of the parameters of the OI and the total OI were compared.

Results: The results of this study confirm the benefits of intrapartum and neonatal outcome, when delivery was carried out in an outpatient setting. The median Ol of intrapartum components was significantly higher in the outpatient setting compared to the hospital maternity ward (97 range from 24 to 100 vs 91 range from 3 to 100). The median Ol of neonatal components was significantly higher in the outpatient compared to the inpatient delivery. (99 range from 97 to 100 vs 96 range from 74 to 100). Certain components from the intrapartum and neonatal period highly contribute to the significantly better total $\mathrm{Ol}$ in the outpatient conditions in relation to hospital conditions.

Conclusion: Outpatient care and delivery provide multiple benefits for both the mother and the newborn.

\section{Introduction}

More and more women find it difficult to come to terms with involuntary hospitalization for the sole purpose of childbirth. This argument stands from the belief that, after a normal pregnancy, there is no need for excessive medicalization for something as natural as childbirth. Numerous worldwide associations support the option of women giving birth at maternity outpatient clinics or even at home. ${ }^{1}$ At the same time, doctors call for caution because the safety of the child and the mother cannot be guaranteed in advance, even after a normal pregnancy. The assessments of requirements that need to be met and what could be characterized as the birth potential constitute the basis for making the right decision regarding childbirth and represent the beginning of proper medical care.

What we would define as a risk factor regarding the delivery itself, the delivery setting, types of delivery, and those in charge of medical care has dominated the decision-making process for decades. ${ }^{1,2}$ While most deliveries take place in hospital clinics or maternity wards, a small percentage ( $1.8 \%$ nationally) take place in outpatient clinics with the assistance of midwives. ${ }^{3}$ 
The very act of giving birth in a hospital has lost some of its humanity. Women are most often halfasleep during childbirth since, in most cases, the pain is relieved by pharmaceuticals.

Pain relief during labor is of course desirable, but sometimes the side effects cannot be avoided. The improvement was made by introducing epidural analgesia as a method of pain control, but this method is still not widely used in obstetric practice as a standard regimen. The mother usually feels abandoned, surrounded by unfamiliar people performing procedures unknown to her. All of this causes stress that can and certainly does affect the course of labor by slowing it down and turning it into something that is described as a cascading intervention. ${ }^{4,5}$ This concept has several drawbacks: it allows for a natural physiological event to be turned into a medical procedure; it restricts a woman's freedom to experience the birth of her children in her own way, in the environment she previously chose; it involves unnecessary interventions; requires a well-equipped hospital and includes all accompanying costs. ${ }^{6}$

Due to all that, delivery in outpatient conditions, primarily outpatient maternity clinics as well as domestic obstetrics, are gaining in popularity. The atmosphere is more personal, more humane, trust in the medical staff is greater and the cooperation between the mother and the staff is better. It also offers the possibility for the father (husband) and other family members to accompany the mother during childbirth. All these facts contribute to the satisfaction and happiness of bringing offspring to the family. However, this practice is not equally represented in the world. The Scandinavian countries, the Netherlands and North America, went the furthest in its implementation, where between $15 \%$ and $30 \%$ of births are performed in outpatient conditions. ${ }^{7}$ There are five outpatient maternity clinics in Montenegro, of which the outpatient maternity clinic in Rožaje is the largest.

In order to prepare and acquire the best conditions for vaginal birth, monitoring, preparation, evaluation and finally the decision on how to complete the birth process requires exceptional commitment to the patient. Pregnancy does not qualify as a pathological category, but it is a physiologically altered condition, and in order for that period to pass as purposefully as possible, increased control of the condition of both the pregnant woman and the fetus is needed, as well as the absolute cooperation and trust between the patient and the obstetrician. For practical reasons, for the purpose of monitoring and controlling a pregnancy we use general rules, protocols, algorithms, questionnaires and indices which significantly facilitate this work.

The optimality index $(\mathrm{OI})$ should be the basis on which the patient's condition before and during pregnancy, during and after childbirth as well as the condition of the fetus and the neonate are based. It was created in the United States of America (USA) in the 1990s, and was modified in 2001 and 2006, as it is still used today with an update every five years. ${ }^{8}$ It is mostly used in the USA, Great Britain and the Scandinavian countries. It implies and cultivates the concept of optimality, which is different from the state of normalcy. ${ }^{9}$

It is based on the maxim "maximum score with minimum intervention". ${ }^{10}$ Turkey and the Netherlands have adjusted the optimality index used in the United States (OI-US) and the results of their studies have 
shown that OI-TR and OI-NL, adapted to the maternity protection system in these countries, are valid and reliable for assessing maternity care. ${ }^{11,12}$

The aim of this study is to use the US based Optimality Index (OI-US) to initiate the possibility of developing an adequate national-level database for women with low- and medium-risk pregnancies and, based on the obtained information from the optimality index, to assess the feasibility and possible application in deciding on delivery settings, as well as in the postpartum and neonatal outcome.

\section{Materials And Methods}

This study is based on prospective monitoring of pregnant women and mothers who were monitored and delivered in the outpatient maternity clinic in Rožaje (100 in total) and pregnant women and mothers who were monitored and delivered at the maternity ward of the General Hospital in Berane (100 in total). Annually, between 130 and 150 births are performed at the outpatient maternity clinic in Rožaje, which is the largest of the five existing such clinics in Montenegro, and about 950 births at the General Hospital in Berane.

The examination was conducted in the 2019-2020 period. All the patients were informed about the reason, methods and manner of conducting the research in the form of a consent form that they were obliged to sign, and written consent for this study was given by the heads of institutions where the research was conducted (General Hospital-Berane, Health Center with outpatient maternity clinic -Rozaje).

In order to ensure homogeneous approximation among the groups, the selected patients were classified according to certain criteria:

The basic criteria for inclusion in the study are:

- age (between 20 and 40),

- multiple births (no more than three pregnancies),

- pregnant women without pre-recorded comorbidity.

Exclusion criteria:

- first birth,

- previous caesarean section or any operation involving a uterine scar (myomectomy, metroplasty, adenomyosis),

- multifetal pregnancy,

- more than three births, 
- women whose pregnancies were the result in vitro fertilization.

\section{Statistical data processing}

Each OI parameter (modified OI that included current pregnancies and childbirth) was evaluated as optimal or not. The obtained results for each parameter are expressed as a percentage or groupation for each of the four components of OI-US: antepartum (12 items), intrapartum (19 items), neonatal (9 items) and postpartum (8 items) as well as the total Optimality Index (48 items).

Measures of descriptive statistics were used to describe the parameters of importance, depending on their nature: frequencies, percentages, medians and range. The Shapiro-Wilk test was used to check the normality of the distribution. In addition to descriptive statistics, the chi-square test, the Fisher test, the Mann-Whitney U-test, and the Median test were used to determine the differences between groups. Multiple logistic regression determined the model where the dependent variable was the place of delivery (outpatient / inpatient). Statistical hypotheses were tested at the level of statistical significance of 0.05 . The SPSS Statistics 22 program (SPSS Inc., Chicago, IL, USA) was used for statistical data processing.

\section{Patient and Public Involvement.}

The patient is informed in the form of a questionnaire in which it is explained in detail what kind of research it is, what is the goal of the research, manner and purpose. The patient was explained that privacy was guaranteed and that he could cancel the research at any time. There were not any randomized controlled trials, instead we compared the result from differently classified groups as it was explained in the protocol of the project. We use this opportunity to thank the patient advisers for the effort, enthusiasm, and the amount of work that they have put into the conduction of this research.

\section{Results}

The results of the study are derived from a sample of 200 pregnant women between the ages of 17 and 45. The mean age of the pregnant women was $30.7 \pm 5.9$. The age of the pregnant women who gave birth out of a hospital was $31.0 \pm 6.6$, the median was 30.0 (range 17-45) and the mean age of women delivered in the hospital was $30.3 \pm 4.9$, median 30.0 (range 20-42). The age of pregnant women did not differ significantly according to the place of delivery, $p=0.498$. The results were observed through antepartum, intrapartum, neonatal and postpartum components.

\section{Antepartum components}

Bleeding in the II and III trimesters of pregnancy was a significant feature in pregnant women who gave birth in hospital conditions (5 cases), while there were no cases in outpatient deliveries $(p=0.024)$. Serious antepartum complications that were not recorded during ongoing pregnancies in subject women were: gestational diabetes, mental illness and Rh sensitization. All other complications characteristic of this stage of pregnancy were represented with an optimal frequency that did not differ significantly in relation to the place of delivery, ie in outpatient or inpatient settings. (Table 1) 
Table 1. Items Available for Analysis for Antepartum Section of the OI $(n=100)$

\begin{tabular}{|llllll|}
\hline Antepartum items & OMW & & HMW & \multirow{2}{*}{ p } \\
\cline { 2 - 5 } & Optimal & Not Optimal & Optimal & Not Optimal & \\
\cline { 2 - 6 } & $\%$ & $\%$ & $\%$ & $\%$ & \\
\hline Anemia & 88 & 12 & 82 & 18 & 0.235 \\
\hline Gestational diabetes & 100 & 0 & 100 & 0 & $/$ \\
\hline Mental disorders & 100 & 0 & 100 & 0 & $/$ \\
\hline Placenta previa & 100 & 0 & 99 & 1 & 1.00 \\
\hline Preeclampsia & 100 & 0 & 99 & 1 & 1.00 \\
\hline Pyelonephritis & 99 & 1 & 99 & 1 & 1.00 \\
\hline Rh sensitization & 100 & 0 & 100 & 0 & $/$ \\
\hline Bleeding in II or III trimesters & 100 & 0 & 95 & 5 & 0.024 \\
\hline Adequate antenatal care & 50 & 50 & 49 & 51 & 0.888 \\
\hline Amniocentesis & 97 & 3 & 100 & 0 & 0.081 \\
\hline Use of medication & 89 & 11 & 84 & 16 & 0.301 \\
\hline NST and BFP & 100 & 0 & 100 & 0 & $/$ \\
\hline
\end{tabular}

* significant $p<0.05$

The previous distribution of antepartum characteristics determined that the median of the total Optimality Index of this component did not differ significantly in relation to the compared groups of pregnant women who were delivered in outpatient or hospital conditions (100 vs $99, p=0.289)$.

\section{Intrapartum components}

Many parameters within the intrapartum period differed significantly depending on the place of delivery (outpatient / inpatient). In hospital conditions, during phase III of childbirth, there was a significantly higher frequency of amniotomy, cesarean section, induction and stimulation of childbirth, application of painkillers and medication other than oxytocin, which are all considered suboptimal characteristics of childbirth. In addition, there were other, less optimal measures taken during childbirth, grade III or IV episiotomy or grade I or II lacerations, fetal heart rate abnormalities, postpartum hemorrhage and blood transfusions that were more appropriate for hospital conditions as suboptimal events.

In the conditions of outpatient preparation and childbirth, according to the global obstetric assessment, epidural analgesia, perineum lacerations which require sutures, and cervical lacerations were suboptimal 
and used with higher frequency. The presence of a support person during childbirth was a favorable feature of outpatient childbirth conditions that was quantified as a significant frequency relative to hospital births. Other intrapartum components did not differ significantly in relation to the delivery setting. Table 2 . 
Table 2

Items Available for Analysis for Intrapartum Section of the OI $(n=100)$

\begin{tabular}{|c|c|c|c|c|c|}
\hline \multirow[t]{3}{*}{ Intrapartum items } & \multicolumn{2}{|l|}{ OMW } & \multicolumn{2}{|l|}{ HMW } & \multirow[t]{3}{*}{$\mathbf{p}$} \\
\hline & Optimal & $\begin{array}{l}\text { Not } \\
\text { Optimal }\end{array}$ & Optimal & $\begin{array}{l}\text { Not } \\
\text { Optimal }\end{array}$ & \\
\hline & $\%$ & $\%$ & $\%$ & $\%$ & \\
\hline $\begin{array}{l}\text { The period between the rupture of the } \\
\text { membrane and birth, }<24 \text { hours }\end{array}$ & 100 & 0 & 100 & 0 & / \\
\hline Amniotomy & 86 & 14 & 49 & 51 & $<.001^{*}$ \\
\hline Clear amniotic fluid & 97 & 3 & 91 & 9 & 0.074 \\
\hline Induction or stimulation of labor & 92 & 8 & 55 & 45 & $<.001^{\star}$ \\
\hline Use of analgesics for labor & 88 & 12 & 55 & 45 & $<.001 *$ \\
\hline Epidural analgesia & 90 & 10 & 97 & 3 & $0.045^{\star}$ \\
\hline Fetal heart rate abnormalities & 100 & 0 & 92 & 8 & $0.004^{*}$ \\
\hline Presence of a support person during labor & 24 & 76 & 7 & 93 & $<.001 *$ \\
\hline Childbirth conditions & 100 & 0 & 95 & 5 & $0.024 *$ \\
\hline Fetus position (cephalic) & 96 & 4 & 95 & 5 & 0.733 \\
\hline Cesarean section & 100 & 0 & 73 & 27 & $<.001^{\star}$ \\
\hline Episiotomy & 95 & 5 & 98 & 2 & 0.248 \\
\hline $\begin{array}{l}\text { Perineal laceration requiring sutures and } \\
\text { cervical lacerations }\end{array}$ & 86 & 14 & 98 & 2 & $0.002 *$ \\
\hline $\begin{array}{l}\text { Grade III or IV episiotomy or grade I or II } \\
\text { lacerations }\end{array}$ & 100 & 0 & 92 & 8 & $0.004 *$ \\
\hline $\begin{array}{l}\text { Medication other than oxytocin during stage } \\
\text { III of childbirth }\end{array}$ & 97 & 3 & 71 & 29 & $<.001 *$ \\
\hline Skin to skin contact & 98 & 2 & 72 & 28 & $<.001 *$ \\
\hline Placental retention longer than 30 minutes & 99 & 1 & 97 & 3 & 0.312 \\
\hline Postpartum haemorrhage & 99 & 1 & 88 & 12 & $<.002 *$ \\
\hline
\end{tabular}




\begin{tabular}{|lllllll|}
\hline Intrapartum items & OMW & & HMW & & p \\
\cline { 2 - 6 } & Optimal & $\begin{array}{l}\text { Not } \\
\text { Optimal }\end{array}$ & Optimal & $\begin{array}{l}\text { Not } \\
\text { Optimal }\end{array}$ & \\
\cline { 2 - 6 } & $\%$ & $\%$ & $\%$ & $\%$ & \\
\hline Blood transfusion & 100 & 0 & 91 & 9 & $<$ \\
\hline
\end{tabular}

*significant $p<0.05$

${ }^{a}$ CTG, Doppler, fetoscopy, CTG finding (non - reactive)

b Unprompted pushing, Postpartum delivery, Instrumental vaginal delivery

The frequency distribution of previously analyzed intrapartum components determined the median of optimal conditions that was significantly higher in outpatient than in hospital delivery settings $(97 \%$ vs $91 \%$ of cases). At the same time, the frequency of suboptimal components was significantly higher in outpatient compared to hospital delivery conditions $(p=0.01 ; 0.05)$.

\section{Neonatal components}

Individually and within neonatal components, the greatest statistical significance belongs to the role of optimal lactation at the time of hospital discharge (up to 72 hours after delivery) in outpatient maternity clinics in relation to hospital maternity wards. This is followed by a higher frequency of optimal neonatal intensive care, then the absence of bacterial infections, as well as the optimal assessment of gestational age, all of which were, in a significantly higher number of cases, appropriate for the outpatient delivery setting. Other neonatal components (infant birth weight, APGAR score at $5 \mathrm{~min}$, congenital anomalies, respiratory distress syndrome), shown in Table 3 , did not differ significantly with respect to the delivery setting. 
Table 3

Items Available for Analysis for Neonatal Section of the OI $(n=100)$

\begin{tabular}{|llllll|}
\hline Neonatal items & OMW & & HMW & P \\
\cline { 2 - 5 } & Optimal & $\begin{array}{l}\text { Not } \\
\text { Optimal }\end{array}$ & Optimal & $\begin{array}{l}\text { Not } \\
\text { Optimal }\end{array}$ \\
\cline { 2 - 5 } & $\%$ & $\%$ & $\%$ & $\%$ & \\
\hline Estimation of gestational age (37-42 weeks) & 99 & 1 & 93 & 7 & $0.030^{*}$ \\
\hline Infant birth weight (2500-4000 gr) & 98 & 2 & 96 & 4 & 0.407 \\
\hline APGAR 5min (7,8,9,10) & 99 & 1 & 97 & 3 & 0.312 \\
\hline Neonatal intensive care & 98 & 2 & 88 & 12 & $0.006^{*}$ \\
\hline Congenital anomalies & 100 & 0 & 98 & 2 & $0.115^{*}$ \\
\hline Bacterial infections other than sepsis & 100 & 0 & 93 & 7 & $<$ \\
\hline Respiratory distress syndrome & & & & & $0.007^{*}$ \\
\hline Other complications including sepsis & 100 & 0 & 100 & 0 & $/$ \\
\hline Lactation at the time discharge (up to 72 & 97 & 3 & 74 & 26 & $<$ \\
\hline hours after delivery) & & & & & 0.567 \\
\hline *. significant $\mathrm{p}<0.05$ & & & & & \\
\hline
\end{tabular}

The median Optimality Index of neonatal components was significantly higher in outpatient compared to inpatient deliveries. At the same time, the median of suboptimal indices was higher in hospital conditions compared to outpatient ones. $(p=0.021$, Graph3.).

\section{Postpartum components}

Local suture infection did not occur in any of the cases of outpatient deliveries during the postpartum period, which is a significant difference compared to six (suboptimal) events in hospital settings ( $p=$ 0.013). At this period, the frequency of prescribed medication in maternity wards was significantly higher in relation to outpatient maternity clinics (15 to 5 cases).

Other postpartum components (perinatal death between the birth and 72 hours of life, cystitis, endometritis) were not observed in outpatient settings. Yet, this is not a significant difference in relation to their prevalence ( $1-2$ cases) in outpatient maternity clinics.

Maternal death, hematoma and mastitis did not occur in any of the cases, regardless of the delivery setting. Table 4.

Table 4. Items Available for Analysis for Postpartum Section of the OI $(n=100)$ 


\begin{tabular}{|llllll|}
\hline Postpartum items & OMW & & HMW & \multicolumn{2}{c|}{ p } \\
\cline { 2 - 5 } & Optimal & $\begin{array}{l}\text { Not } \\
\text { Optimal }\end{array}$ & Optimal & $\begin{array}{l}\text { Not } \\
\text { Optimal }\end{array}$ \\
& $\%$ & $\%$ & $\%$ & $\%$ & \\
\hline $\begin{array}{l}\text { Perinatal death occurring between birth and } \\
72 \text { hours }\end{array}$ & 100 & 0 & 99 & 1 & 1.00 \\
\hline Cystitis & 100 & 0 & 99 & 1 & 1.00 \\
\hline Endometritis & 100 & 0 & 98 & 2 & 0.155 \\
\hline Hematoma & 100 & 0 & 100 & 0 & $/$ \\
\hline Local suture infection & 100 & 0 & 94 & 6 & $0.013^{\star}$ \\
\hline Mastitis & 95 & 5 & 95 & 5 & 1.00 \\
\hline Prescribed medication & 95 & 5 & 85 & 15 & $0.018^{*}$ \\
\hline Maternal death & 100 & 0 & 100 & 0 & $/$ \\
\hline
\end{tabular}

*. significant $p<0.05$

The median Optimality Index for previously analyzed postpartum components, was at the border of statistically significant differences in relation to the place of delivery: outpatient or inpatient $(100 \% \mathrm{vs}$ $98.5 \%, p=0.050)$. Graph 4 .

The Total Optimality Index (OI) contained all of the synthesized, previously analyzed parameters of individual components (48 items). For the considered sample of subjects, the median total optimality index (which included antepartum, intrapartum, neonatal and postpartum components) was in the $99 \%$ range $(24 \%-100 \%)$ for the outpatient maternity clinics as opposed to the hospital maternity wards where it was in the $96 \%$ range ( $3 \%-100 \%)$. Statistical testing of the significance of differences shows that this difference is significant, at the adopted level of reliability, and favors the optimality of delivery conditions in outpatient settings. ( $p=0.001$, Graph 5$)$.

\section{Logistic regression analysis}

All variables that stood out as statistically significant for the alpha level of 0.001 in the primary analysis were inserted into the logistic regression model where delivery settings (outpatient / inpatient conditions) represented the dependent variable. 
Table 5

Logistic regression

\begin{tabular}{|c|c|c|c|}
\hline \multirow[t]{2}{*}{ Independent variables } & \multicolumn{3}{|c|}{ Multiple logistic regression } \\
\hline & B & $\mathbf{p}$ & OR $(95 \% \mathrm{Cl})$ \\
\hline Amniotomy & 1.39 & $0.003^{*}$ & $4.01(1.63-9.91)$ \\
\hline Induction or stimulation of labor & 18.88 & 0.997 & $\begin{array}{l}157556047.7 \\
(0.0-/)\end{array}$ \\
\hline Use of painkillers & -18.19 & 0.998 & $0.0(0.0-0.0)$ \\
\hline The presence of a person of support during childbirth & -1.53 & $0.007 *$ & $0.22(0.07-0.66)$ \\
\hline Cesarean section & 35.356 & 0.997 & $2.2 \mathrm{e}^{15}(0.0-/)$ \\
\hline Medication other than oxytocin during stage III of childbirth & -0.29 & 0.779 & $0.75(0.10-5.51)$ \\
\hline Skin to skin contact & 0.03 & 0.980 & $1.03(0.09-11.83)$ \\
\hline $\begin{array}{l}\text { Lactation at the time discharge (up to } 72 \text { hours after } \\
\text { delivery) }\end{array}$ & -1.24 & 0.082 & $0.29(0.07-1.17)$ \\
\hline
\end{tabular}

The model contains 8 independent variables and the whole model was statistically significant (chi-square $=84.877, \mathrm{p}<0.001)$, Table 5 .

In the multiple logistic regression model, amniotomy was singled out as a statistically significant factor in delivery in hospital conditions $(B=1.39 ; p=0.003)$, and pregnant women who underwent amniotomy 4 times were more likely to give birth in hospital conditions. However, the presence of a support person during childbirth is a significant factor that increases the chance of pregnant women opting for delivery in outpatient settings $(B=-1.53 ; p=0.003)$.

Another distinguishing factor is lactation at the time of hospital discharge (up to 72 hours after delivery), which is closer to the statistical significance than other variables in the model and indicates that the successful onset of lactation before discharge is another factor in favor of outpatient delivery $(B=-1.24$; $p=0.082)$.

\section{Discussion}

The main goal of the presented study was to quantify and compare the optimal outcome factors in maternity and neonatal care in inpatient and outpatient deliveries. The aspiration was to achieve the optimal conditions of pregnant women and mothers that would guarantee adequate prerequisites for physiological childbirth. Maternity care models have a basis in the scientific literature that shows the existing relationship between the quality of care and the data on the related support. However, the outcome commonly presented in the maternity support data is usually only limited to the presence of morbidity and mortality in women and their newborns. In that sense, the full range of childbirth 
experience is not included, nor is the medical support that would promote optimal care conditions, which is often a consequence of the lack of an appropriate measuring system for this type of care. ${ }^{13}$

The Optimality Index used as a measuring instrument in this study included only one part of the original OI-US score. Namely the first part, the Perinatal Background Index PBI (demographic, medical, and obstetric history factors) is not presented in our paper since the attention was placed on the Optimality Index.

The Optimality Index (OI) is a combined measure of antepartum, intrapartum, neonatal, and postpartum care practices and health outcomes. Over time, the concept of optimality and its components has undergone numerous changes and, if necessary, reductions. ${ }^{8,14,15}$

The advantages of different versions of outpatient delivery conditions have been noticeably considered with reference to several varieties of beneficial effects of such an approach. Among the many observed benefits, we can distinguish an increase in the probability of vaginal births, a lower rate of interventions, including epidural anesthesia, and a shorter labor duration. ${ }^{16-21}$

The total Optimality Index in this paper is very high in outpatient maternity clinics (median $99 \%$ range $24-100 \%$ ), but also in hospital maternity wards (96\% range $3-100 \%)$. For the considered sample of subjects, the median of the Total Optimality Index (which included antepartum, intrapartum, neonatal and postpartum components) was significantly higher in the outpatient maternity clinics.

The results of other authors also show significantly high medians or average scores of optimality indices (total or by components). Numerous factors limit the direct comparison of our results with other studies. This implies the differences in design and methods, with respect for randomization, analysis in accordance with the intended and current place of delivery, present risk and similar. Compared to most studies of this subject matter, the concept of low-risk pregnancies was quite restrictive. Thus, the exclusion criteria in the study included many characteristics that were accepted in other studies. Comparisons of other research results often included the division of pregnant women by parity, by place of delivery (rural-urban environment), whether caesarean section occurred or not, whether epidural was administered or not and some other delivery conditions. ${ }^{13,18,22,23}$

To observe the outcome of deliveries and the quality of care in the appropriate conditions through the parameters of morbidity / mortality of mothers and newborns would require many years of research with a huge amount of analyzed data (meta-analyzes) since, fortunately, these occurrences are not frequent. $^{21,24}$

By comparing the obtained optimality indices by components, we noticed that the significant differences in relation to the place of care and child delivery occur mostly during the intrapartum and then in the neonatal period. The median optimality index of intrapartum components was significantly higher in the outpatient delivery settings compared to the inpatient maternity ward (97 range from 24 to 100 vs 91 range from 7 to 100). In hospital conditions, the use of caesarean section as a mode of delivery was 
noticeable, as well as the application of other physically invasive measures during delivery, such as the significantly higher frequency of amniotomy, induction and stimulation of childbirth, application of painkillers, all of which are considered suboptimal characteristics of the course of child delivery. The higher frequency of interventions during childbirth and oxytocin usage was confirmed by a study conducted in Australia in the 2000-2012 period. ${ }^{25}$ Women who plan to give birth in outpatient maternity clinics are twice as likely to have a vaginal birth compared to women who plan to give birth in hospitals. $^{24}$

In all comparative analyzes, the rate of cesarean deliveries occurring in hospital conditions has been proven to be significantly higher compared to alternative delivery settings that included private clinics and home deliveries with adequate assistance from midwives or other medical staff. ${ }^{25-29}$ However, there may be some limitations in such analyzes, so the possibility of direct comparison must be considered within the conditions in which the delivery took place and taking into account many factors, including parity, epidural analgesia, oxytocin administration, transfer rate, medical staff proficiency and similar. ${ }^{21}$ Therefore, the approach to such comparisons requires the application of much more rigorous descriptions of conditions. ${ }^{24}$

Back in 2002, a research was conducted in the US by The Maternity Center Association (MCA) with the aim of pointing out that a technologically-invasive childbirth is a significant experience for most women in the US, with increasing tendency to promote technological benefits to support best pregnancy health outcomes. ${ }^{22}$ It has been proven that, even though many practices are not effectively supported by the scientific literature, they are routinely applied during perinatal care in healthy women. Following the findings of previous and similar research, group organizations have been formed, advocating for a less technological approach to maternity care and calling for the application of less technologically oriented practices and increasing the number of options for pregnant women. (Coalition for Improving Maternity Services, 1996; Sakala, Gyte, Henderson, Neilson, \& Horey, 2001).

Contrary to many research results, in this study, laceration as an intrapartum component had a significant frequency in outpatient deliveries, which coincides with the results of the Dutch birth center study, obtained using OI-NL2015, especially in nulliparous women. ${ }^{30}$ There are reasons described in the literature that could be responsible for this suboptimal component. Higher degree of perinatal laceration includes obstetric and neonatal factors and characteristics of the newborn. Possible factors include mothers' higher body weight, and often related newborns' higher body weight, but also the application of instrumental vaginal births. ${ }^{31}$

The presence of a support person during childbirth was proven to be a favorable feature of outpatient delivery but also, as proven through a logistic regression analysis, a factor that increases the chance of pregnant women opting for outpatient delivery. Most analyzes of perinatal conditions from the literature confirm the importance of this factor in the intrapartum process. ${ }^{18,19}$ 
In the neonatal period, the most important optimality component is lactation at the time of hospital discharge (up to 72 hours after giving birth), followed by a significantly less suboptimal presence of bacterial infections and optimal gestational age.

The application of logistic regression analysis also confirmed that certain components from the intrapartum and neonatal period contribute the most to the significantly better total optimality index in outpatient conditions compared to hospital conditions.

Our research operationalized this approach, with enough perspective data to satisfy the sample size calculations. This study offers a broad overview of relevant factors in contemplating the physiology of childbirth in the outpatient delivery approach in Montenegro, including the assessment of validity, and is the first such study in the Balkans. This was also the first time the Ol was used in Montenegro to support physiological childbirth. The design of the study was prospective, which made it possible to monitor the pregnancy of each pregnant woman from the beginning of gestation to delivery. Since only one outpatient maternity clinic is involved, this can be considered a disadvantage of this study.

\section{Conclusion}

Outpatient care and delivery provide multiple benefits for both the mother and the newborn. The results of this study, based on the comparison of basic components and the total Optimality Index, confirm the benefits of intrapartum and neonatal outcome, when delivery was performed in an outpatient setting. Also, the total Optimality Index has a better score in outpatient compared to inpatient conditions.

\section{Declarations}

\section{Acknowledgements}

The authors gratefully acknowledge the work of Dr Nenad Šulović for her work on this project.

Author Contributions: Conceptualization, data curation: A.L. and A.I.; formal analysis: A.I., N.Š, M.M; investigation, methodology: A.L., N.Š., D.T., S.S., A.I. and M.M; supervision: N.Š., M.M; validation, writingoriginal draft: A.L., N.Š., A.I., and M.M; writing-review and editing: A.L and S.S. All authors have read and agreed to the published version of the manuscript.

Competing interests: The authors declared no potential conflicts of interest with respect to the research, authorship, and/or publication of this article.

Funding: The authors received no specific funding for this work.

Consent for publication: Not applicable.

Ethics approval and consent to participate: The research project was in accordance with the Declaration of Helsinki, and was approved by the management of the Rožaje Health Center with an outpatient 
maternity hospital, decision number 131 date: $31 / 01 / 2020$. as well as the management of the General Hospital Berane, decision number 746 date: 04/02/2020.

In Montenegro, Ethics Committees are bodies that exist in scientific and educational institutions, such as faculties. Health care institutions in Montenegro do not have ethics committees. The consent given by the health institution obliges to respect all ethical principles, which is regulated by the legal acts of that institution.

Informed Consent Statement: Informed consent was obtained from all subjects involved in the study.

Data Availability Statement: The data presented in this study are available on reasonable request from the corresponding author.

\section{References}

1. National Perinatal Epidemiology Unit, University of Oxford. BMJ. 2011; 343.

2. UNFPA, ICM, WHO. State of the World's Midwifery 2011: Delivering health, saving lives. 2011; UNFPA: New York http:// Google Scholar

3. Australian Institute of Health and Welfare 2017. Australia's mothers and babies 2015-in brief. Perinatal statistics series no. 33. Cat no. PER 91. Canberra: AlHW.

4. Hodnett ED, Gates S, Hofmeyr GJ, Carol Sakala C. Continuous support for women during childbirth. Cochrane Database of Systematic Reviews. 2013;7:CD003766. doi: 1002/14651858.CD003766.pub5.

5. Green J, Amis D, Hotelling BA. Care practice 3. Continuous labor support. J Perinat Educ. 2007; 16(3): 25-28. doi: 10.1624/105812407X217110

6. Tunçalp Ö, Were WM, MacLennan C, Oladapo OT, Gülmezoglu AM, Bahl R, et al. Quality of care for pregnant women and newborns - the WHO vision. BJOG. 2015.;122(8):1045-9. doi: 10.1111/14710528.13451.

7. Hendrix M, Van Horck M, Moreta D, Nieman F, Nieuwenhuijze M, Severens J, Nijhuis J. Why women do not accept randomisation for place of birth: feasibility of a RCT in the Netherlands. BJOG: an International Journal of Obstetrics and Gynaecology. 2009;116 4.: 537-544. doi: 10.1111/j.14710528.2008.02103.x.

8. Murphy PA, Fullerton JT. Development of the Optimality Index as a new approach to evaluating outcomes of maternity care. J Obstet Gynecol Neonatal Nurs. 2006;35(6):770-doi: 10.1111/j.15526909.2006.00105.x.

9. Kennedy H. A concept analysis of optimality in perinatal health. J Obstet Gynecol Neonatal Nurs. 2006;35(6):763-9. doi: 10.1111/j.1552-6909.2006.00104.x.

10. Wiegers TA, Keirse MJ, Berghs GA, van der Zee J. An approach to measuring quality of midwifery care. J Clin Epidemiol. 1996. 49(3):319-325. doi: 10.1016/0895- (95)00549-8. 
11. Cigdem Yucel, Lale Taskin, Lisa Kane Low. Validity and reliability of the Turkish version of the Optimality Index-US (OI-US) to assess maternity care outcomes. Midwifery. 2015;31(12):1135-42. doi: 10.1016/j.midw.2015.08.003.

12. Suzanne M Thompson, Marianne J Nieuwenhuijze, Luc Budé, Raymond de Vries, Lisa Kane Low. Creating an Optimality Index - Netherlands: a validation study. BMC Pregnancy Childbirth. 2018;18(1):100. doi: 10.1186/s12884-018-1735-z.

13. Patricia Aikins Murphy and Judith T. Fullerton. Measuring outcomes of midwifery care: development of an instrument to assess optimality. J Midwifery Womens Health. 2001.;46(5):274-84. doi: 10.1016/s1526-9523(01)00158-1.

14. Kyllerman M, Hagberg G. Reduced optimality in pre- and perinatal conditions in a Swedish newborn population. Neuropediatrics 1983;14(1):37-42. doi: 10.1055/s-2008- 1059550.

15. Touwen B, Huisjes H, Jurgens-van der Zee AD, Bierman-van Eendenburg M, Smrkovsky M, Olinga A. Obstetrical condition and neonatal neurological morbidity. An analysis with the help of the optimality concept. Early Hum Dev. 1980;4(3):207-28. doi: 10. 1016/0378-3782(80)90027-4.

16. World Health Organization. WHO recommendations: intrapartum care for a positive childbirth experience. Geneva: World Health Organization; 2018.

17. Oladapo OT, Tunçalp Ö, Bonet M, Lawrie TA, Portela A, Downe S, et al. WHO model of intrapartum care for a positive childbirth experience: transforming care of women and babies for improved health and wellbeing. BJOG. 2018; 125(8):918-22. doi: 10. 1111/1471-0528.15237.

18. Bohren MA, Hofmeyr GJ, Sakala C, Fukuzawa RK, Cuthbert A. Continuous support for women during childbirth. Cochrane Database Syst Rev. 2017;7(7):CD003766. doi: 10. 1002/14651858.CD003766.pub6.

19. Sandall J, Soltani H, Gates S, Shennan A, Devane D. Midwife-led continuity models versus other models of care for childbearing women. Cochrane Database Syst Rev. 2016.;4:CD004667. doi: 10.1002/14651858.CD004667.pub5.

20. McLachlan HL, Forster DA, Davey MA, Farrell T, Gold L, Biro MA, et al. Effects of continuity of care by a primary midwife (caseload midwifery) on caesarean section rates in women of low obstetric risk: the COSMOS randomised controlled trial. BJOG. 2012.;119(12):1483-92. doi: 10.1111/j.14710528.2012.03446.x.

21. Brocklehurst $P$, Hardy $P$, Hollowell J, Linsell L, Macfarlane A, McCourt C, et al. Perinatal and maternal outcomes by planned place of birth for healthy women with low risk pregnancies: the Birthplace in England national prospective cohort study: birthplace in England collaborative group. BMJ. 2011;343:d7400. doi: 10.1136/bmj.d7400

22. Lisa Kane Low and Janis Miller. A clinical evaluation of evidence- based maternity care using the Optimality Index. J Obstet Gynecol Neonatal Nurs. 2006;35(6):786 - 93. doi: 10. 1111/j.15526909.2006.00107.x.

23. Elizabeth Nethery, Wendy Gordon, Marit L. Bovbjerg. Rural community birth: Maternal and neonatal outcomes for planned community births among rural women in the United States, 2004-2009. 
Birth.2018;45(2):120-129. doi: 10.1111/birt.12322.

24. Scarf VL, Rossiter C, Vedam S, Dahlen HG, Ellwood D, Forster D, et al. Maternal and perinatal outcomes by planned place of birth among women with low-risk pregnancies in high-income countries: a systematic review and meta-analysis. Midwifery. 2018.;62:240-55. doi:

10.1016/j.midw.2018.03.024.

25. Caroline SE Homer, Seong L Cheah, Chris Rossiter, Hannah G Dahlen, David Ellwood, Maralyn J Foureur, et al. Maternal and perinatal outcomes by planned place of birth in Australia 2000-2012: a linked population data study. BMJ Open. 2019:;9(10):e029192. doi: 10.1136/bmjopen-2019-029192.

26. Scupholme A, McLeod AG, Robertson EG. A birth center affiliated with the tertiary care center: Comparison of outcome. Obstet Gynecol.1986;67(4):598-603.

27. Jackson DJ, Lang JM, Swartz WH, Ganiats TG, Fullerton J, Ecker J, et al. Outcomes, safety, and resource utilization in ac ollaborativecare birth center program compared with traditiona Iphysicianbased perinatal care. Am J Public Health. 2003; 93(6):999-1006. doi: 10.2105/ajph.93.6.999.

28. Feldman E, Hurst M. Outcomes and procedures in low risk birth: A comparison of hospital and birthcenter settings. Birth.1987;14(1):18-24. https://doi.org/10.1111/j.1523- 536. X.1987.tb01444.x

29. David M, vonSchwarzenfeld HK, Dimer J, Kentenich H. Perinatal outcome in hospital and birth center obstetric care. Int J Gynaecol Obstet. 1999;65(2):149-156. doi: 10. 1016/s0020-7292(99)00038 - 7.

30. Marieke A A Hermus, Marit Hitzert, Inge C Boesveld, M Elske van den Akker-van Marle, Paula van Dommelen, Arie Franx, et al. Differences in optimality index between planned place of birth in a birth centre and alternative planned places of birth,a nationwide prospective cohort study in The Netherlands: results of the Dutch Birth Centre Study. BMJ Open. 2017;7(11):e016958. doi: 10.1136/bmjopen-2017-016958.

31. Waltraut M. Merz, Laura Tascon-Padron, Marie-Therese Puth, Andrea Heep, Sophia L. Tietjen, Matthias Schmid, Ulrich Gembruch. Maternal and neonatal outcome of births planned in alongside midwifery units: a cohort study from a tertiary center in Germany. BMC Pregnancy Childbirth. 2020;20(1):267. doi: 10.1186/s12884-020-02962-4.

\section{Figures}




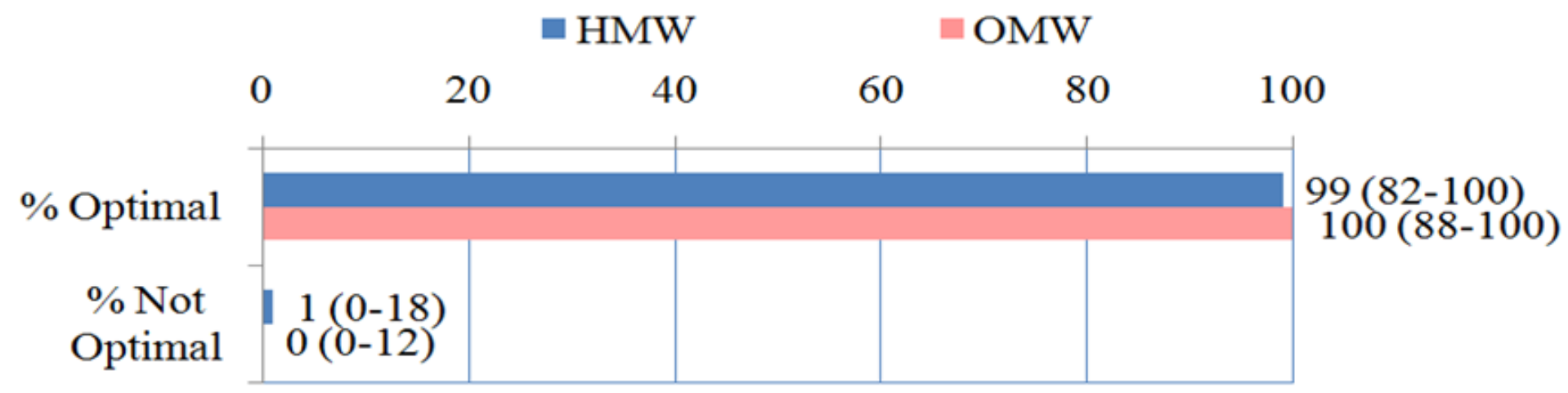

antepartum

Figure 1

The total OI score for Antepartum Section - MEDIAN (range)

- HMW $\quad$ OMW

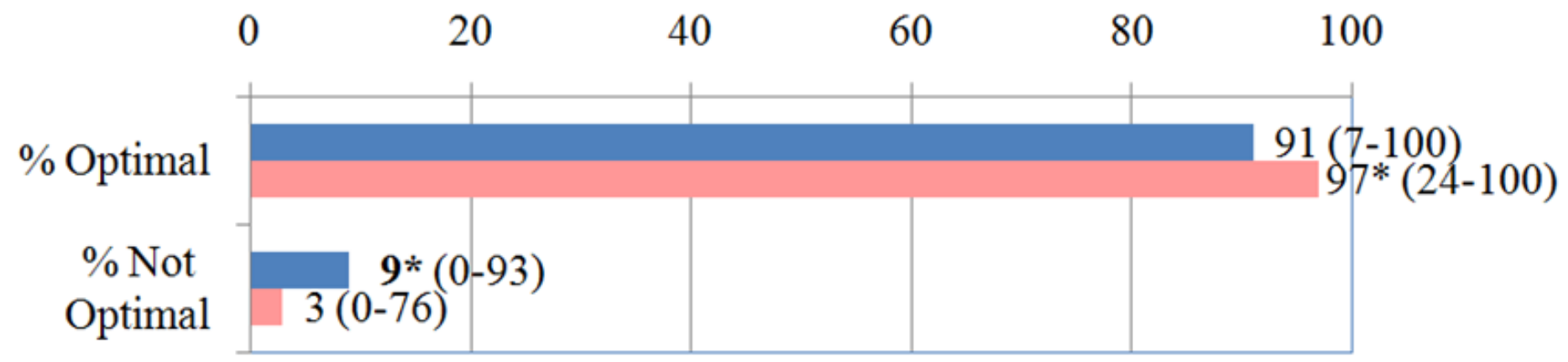

intrapartum

* significantly p<0.05

Figure 2

The total OI score for Intrapartum Section - MEDIAN (range) 


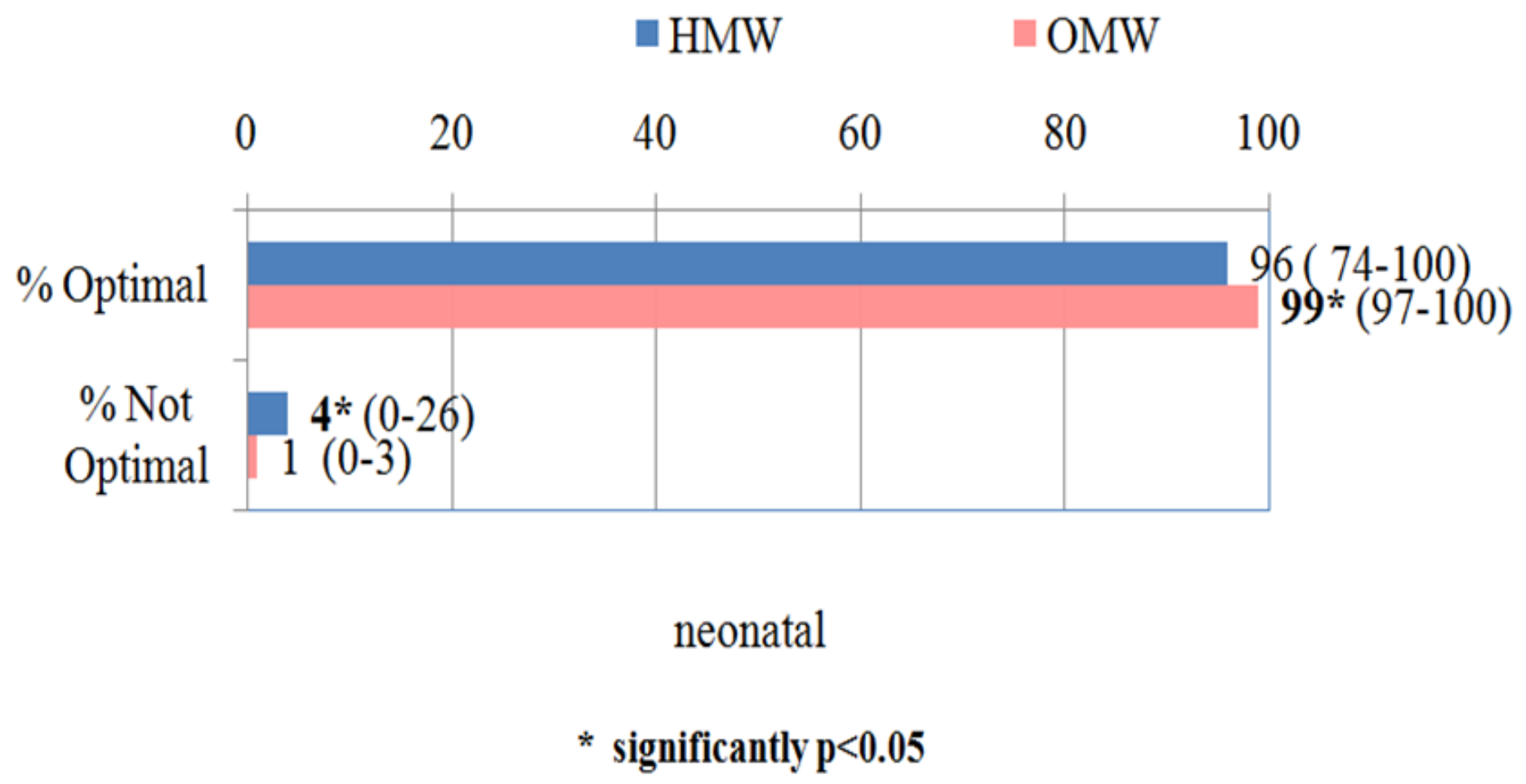

Figure 3

The total OI score for Neonatal Section MEDIAN (range)

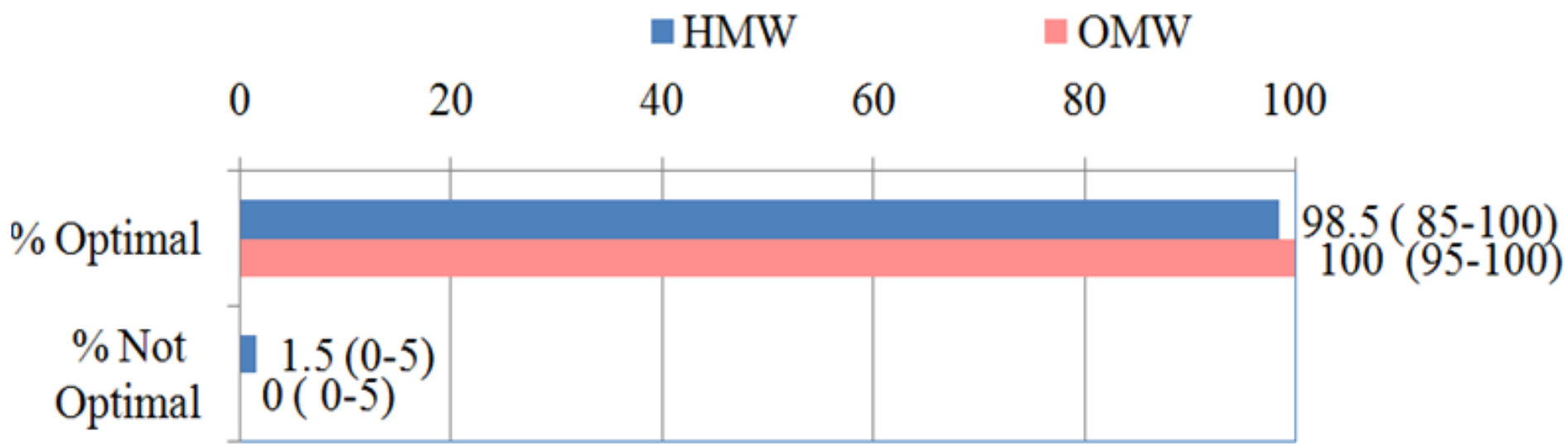

postpartum

Figure 4

The total OI score for Postpartum Section MEDIAN (range) 


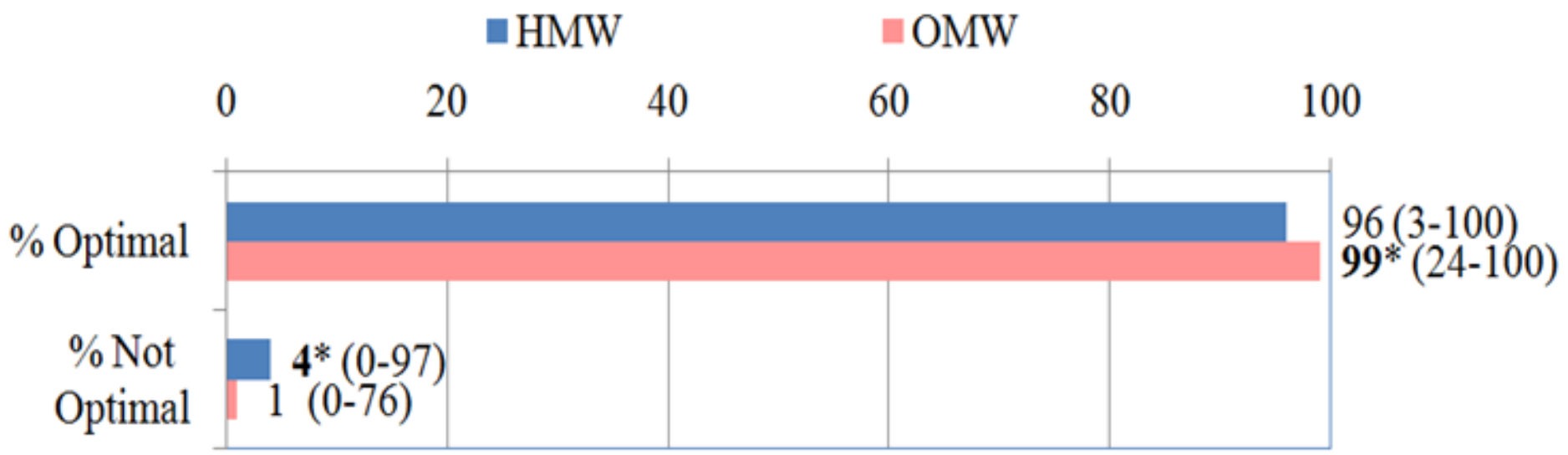

The total OI score - MEDIAN (range)

* significantly $\mathrm{p}<0.05$

Figure 5

The total OI score MEDIAN (range) 